\title{
Transsacral Osseous Corridor Anatomy Is More Amenable To Screw Insertion In Males: A Biomorphometric Analysis of 280 Pelves
}

\author{
Florian Gras PD Dr med, Heiko Gottschling Dr rer nat, \\ Manuel Schröder Dr rer nat, Ivan Marintschev DM, \\ Gunther O. Hofmann Prof Dr med Dr rer nat, Rainer Burgkart PD Dr med
}

Received: 23 February 2016/Accepted: 20 June 2016/Published online: 8 July 2016

(C) The Association of Bone and Joint Surgeons $\mathbb{R} 2016$

\begin{abstract}
Background Percutaneous iliosacral screw placement is the standard procedure for fixation of posterior pelvic ring lesions, although a transsacral screw path is being used
\end{abstract}

Two of the authors certify that they (FG, IM), or a member of their immediate families, has or may receive payments or benefits, during the study period, an amount of less than USD 10,000, from Stryker GmbH (Selzach, Germany).

Two of the authors certify that they (HG, MS), or a member of their immediate families, has or may receive payments or benefits, during the study period, an amount of USD 10,000-100,000 from Stryker GmbH (Selzach, Germany).

One of the authors $(\mathrm{RB})$ certifies that he, or a member of his immediate family, has or may receive, during the study period, an amount of less than USD 10,000 from Stryker GmbH (Selzach, Germany).

All ICMJE Conflict of Interest Forms for authors and Clinical Orthopaedics and Related Research ${ }^{\mathbb{R}}$ editors and board members are on file with the publication and can be viewed on request.

Clinical Orthopaedics and Related Research ${ }^{\circledR}$ neither advocates nor endorses the use of any treatment, drug, or device. Readers are encouraged to always seek additional information, including FDAapproval status, of any drug or device prior to clinical use.

Each author certifies that his institution approved or waived approval for the human protocol for this investigation and that all investigations were conducted in conformity with ethical principles of research.

This work was performed at the University Hospital (Jena, Germany) and the Klinikum rd Isar, Technische Universität (München, Germany).

F. Gras ( $\bowtie)$, I. Marintschev, G. O. Hofmann

University Hospital Jena, Friedrich-Schiller University, Jena,

Germany

e-mail: florian.gras@med.uni-jena.de

H. Gottschling, M. Schröder, R. Burgkart

Clinic of Orthopaedics and Sportsorthopaedics, Klinikum rd Isar,

Technische Universität München, Munich, Germany more frequently in recent years owing to increased fracture-fixation strength and better ability to fix central and bilateral sacral fractures. However, biomorphometric data for the osseous corridors are limited. Because placement of these screws in a safe and effective manner is crucial to using transsacral screws, we sought to address precise sacral anatomy in more detail to look for anatomic variation in the general population.

Questions/purposes We asked: (1) What proportion of healthy pelvis specimens have no transsacral corridor at the level of the S1 vertebra owing to sacral dysmorphism? (2) If there is no safe diameter for screw placement in the transsacral S1 corridor, is an increased and thus safe diameter of the transsacral S2 corridor expected? (3) Are there sex-specific differences in sacral anatomy and are these correlated with known anthropometric parameters?

Methods CT scans of pelves of 280 healthy patients acquired exclusively for medical indications such as polytrauma (20\%), CT angiography (70\%), and other reasons (10\%), were segmented manually. Using an advanced CT-based image analysis system, the mean shape of all segmented pelves was generated and functioned as a template. On this template, the cylindric transsacral osseous corridor at the level of the S1 and S2 vertebrae was determined manually. Each pelvis then was registered to the template using a free-form registration algorithm to measure the maximum screw corridor diameters on each specimen semiautomatically.

Results Thirty of 280 pelves (11\%) had no transsacral S1 corridor owing to sacral dysmorphism. The average of maximum cylindrical diameters of the $\mathrm{S} 1$ corridor for the remaining 250 pelves was $12.8 \mathrm{~mm}(95 \% \mathrm{CI}, 12.1-13.5$ $\mathrm{mm}$ ). A transverse corridor for S2 was found in 279 of 280 pelves, with an average of maximum cylindrical diameter of $11.6 \mathrm{~mm}$ (95\% CI, 11.3-11.9 mm). Decreasing 
transsacral S1 corridor diameters are correlated with increasing transsacral $\mathrm{S} 2$ corridor diameters ( $\mathrm{R}$ value for females, $-0.260, \mathrm{p}<0.01$; for males, -0.311 , $\mathrm{p}<0.001)$. Female specimens were more likely to have sacral dysmorphism (defined as a pelvis without a transsacral osseous corridor at the level of the S1 vertebra) than were male specimens (females, 16\%; males, 7\%; p < 0.003). Furthermore female pelves had smaller-corridor diameters than did male pelves (females versus males for $\mathrm{S} 1: 11.7 \mathrm{~mm} \mathrm{[95 \%} \mathrm{CI}$, $10.6-12.8 \mathrm{~mm}$ ] versus $13.5 \mathrm{~mm}$ [95\% CI, 12.6-14.4 mm], $\mathrm{p}<0.01$; and for S2: $10.6 \mathrm{~mm}$ [95\% CI, 10.1-11.1 mm] versus $12.2 \mathrm{~mm}$ [95\% CI, 11.8-12.6 mm ], p < 0.0001).

Conclusions Narrow corridors and highly individual, sexdependent variance of morphologic features of the sacrum make transsacral implant placement technically demanding. Individual preoperative axial-slice CT scan analyses and orthogonal coronal and sagittal reformations are recommended to determine the prevalence of sufficient-sized osseous corridors on both levels for safe screw placements, especially in female patients, owing to their smaller corridor diameters and higher rate of sacral dysmorphism.

\section{Introduction}

Percutaneous screw fixation of the posterior pelvic ring is commonly used to treat unstable pelvic ring lesions $[9,12,13,20,25,27,30,35]$. Iliosacral osseous corridors exist at the first and second sacral vertebral levels. Whereas the main corridor axis alignment is horizontal on the second sacral vertebra, two different osseous corridors can be addressed on the first sacral vertebra, depending on the individual sacral shape and fracture pattern (Fig. 1): (1) oblique iliosacral screw trajectory $[2,5,20]$; and (2) transverse transsacral screw trajectory $[5,9,12,24,25,35]$.

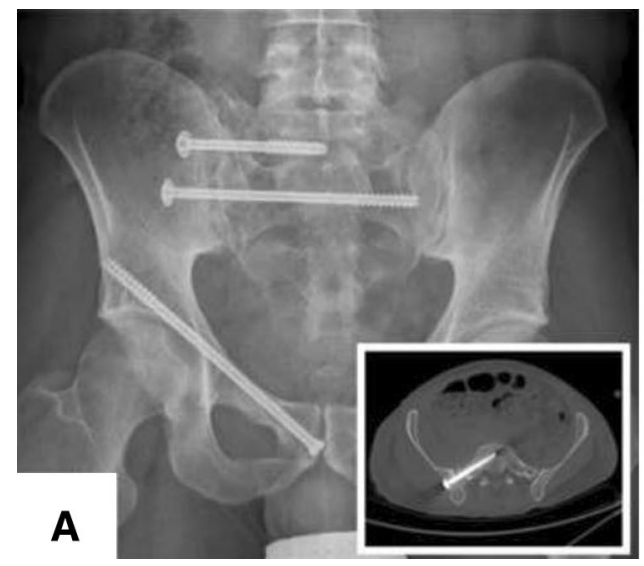

Fig. 1A-B (A) An oblique iliosacral screw position at the level of S1 and a transverse transsacral screw position on the level of S2 are displayed to fix a pelvic ring fracture (AO/OTA classification, $61 \mathrm{C} 1.2 .2 \mathrm{c} 1$ ) in a dysmorphic sacrum. (B) Two transverse transsacral
The advantage of transverse screw placement is the opportunity to address central Denis Zone III [6] and bilateral sacral fractures by transsacral fixation with longer screws. Furthermore, increased fixation strength was reported for longer screws in biomechanical studies $[18,33]$. The drawback of transsacral screw fixation is the difficult placement owing to the individual variable three-dimensional anatomic shape of the sacrum (sacral dysmorphism), with several neurovascular structures in close proximity to the osseous boundary (S1 corridor: L4 and L5 nerve route and internal iliac vessels above and in front of the sacral alar region; $\mathrm{S} 1$ nerve route and the residual nerve pairs in the spinal canal below and posterior; S2 corridor: S1 foramen with its nerve route above and S2 foramen with its nerve route below) [3, 7, 34]. Furthermore there is limited ability to see all relevant bony structures on the intraoperative two-dimensional fluoroscopic images [7, 22, 29, 31, 40]. The corridor for the oblique sacroiliac screw placement in the first vertebra has been investigated in different biomorphometric studies [2, 7, 8, 16], but data for transverse transsacral screw placement at the level of S1 and S2 are limited owing to the small size of study groups, different exclusion criteria, or measurement techniques [11, 22, 23, 37, 39].

Therefore, CT data sets of 280 healthy pelves were evaluated to answer the following study questions: (1) What proportion of healthy pelvis specimens have no transsacral corridor at the level of the S1 vertebra owing to sacral dysmorphism? (2) If there is no safe diameter for screw placement in the transsacral S1 corridor, is an increased and thus safe diameter of the transsacral S2 corridor expected? (3) Are there sex-specific differences in sacral anatomy and are these correlated with known anthropometric parameters?

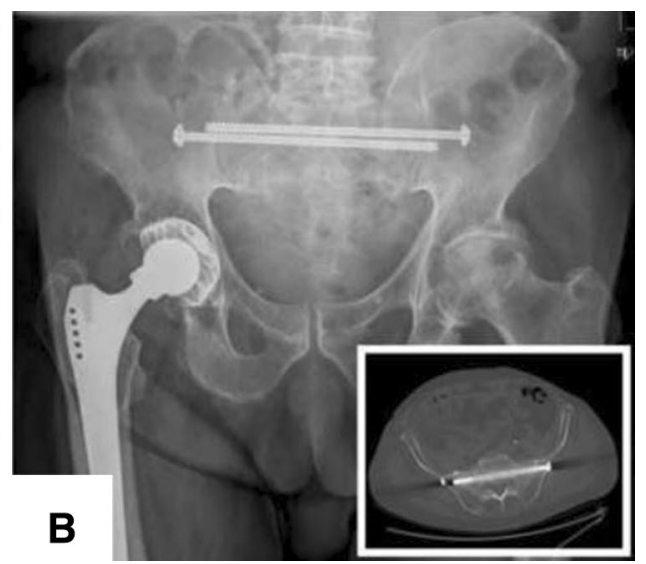

screws were inserted at the level of S1 to fix a jumpers fracture (RoyCamille Type 1). The inserts in the lower right corner show the screw positions in representative axial CT-slices. 
Table 1. Sex-specific differences of anthropometric parameters

\begin{tabular}{llll}
\hline Data set & Overall $(\mathrm{n}=280)$ & Female $(\mathrm{n}=116)$ & Male $(\mathrm{n}=164)$ \\
\hline Age (years) & & & $\mathrm{p}$ value \\
Mean & 63 & 63 & 63 \\
$95 \%$ CI & $60-65$ & $59-66$ & $20-93$ \\
Range & $19-93$ & $19-93$ & \\
Body height $(\mathrm{cm})$ & & & 175 \\
Mean & 171 & 164 & $174-176$ \\
$95 \%$ CI & $170-172$ & $163-166$ & $154-196$ \\
Range & $142-196$ & $142-181$ & 0.0001 \\
Body weight $(\mathrm{kg})$ & & & 83 \\
Mean & 79 & 73 & $80-86$ \\
$95 \%$ CI & $77-81$ & $70-76$ & $48-135$ \\
Range & $45-135$ & $45-120$ & 0.0001 \\
\hline
\end{tabular}

NS $=$ not significant

\section{Materials and Methods}

The evaluation was performed on a set of 280 segmented pelvis specimens (Table 1) available as triangulated surface meshes in an advanced image analysis system developed by a team from Technische Universität München in cooperation with Stryker Trauma GmbH (Kiel, Germany). All segmentations were performed manually by a radiologist (GK), based on CT scans acquired exclusively for medical indications: polytrauma (20\%), CT angiography $(70 \%)$, and other reasons (10\%), before this study was designed. Pelves with fractures, pelvic ring deformity, hip dysplasia, or hardware in situ were excluded. The scans were collected with the consent of the patients.

The specimens were processed as described [10, 32]. A mean shape (the template) was generated from all input data sets (Fig. 2). The individual specimens (the samples) were registered to the template using a free-form registration algorithm that yields a dense surface mapping from points located on the template to anatomically corresponding points on the samples.

For our analysis, a point was placed in each of the two corridors of S1 and S2 on the template. Through the mapping algorithm, the two points were transferred to each sample to determine the patient-specific location of these points. In the mediolateral direction, a transsacral axis for each corridor was defined individually. Starting with this initial axis, a fitting procedure identifies the cylinder with the greatest diameter that can be placed in the osseous corridor without penetrating the cortical regions (at the superior and anterior sacral surface, neuroforamen wall, or spinal canal). To do that, the sample meshes are projected along the axis to generate component images for each corridor. An image pixel is set if no cortical bone structure

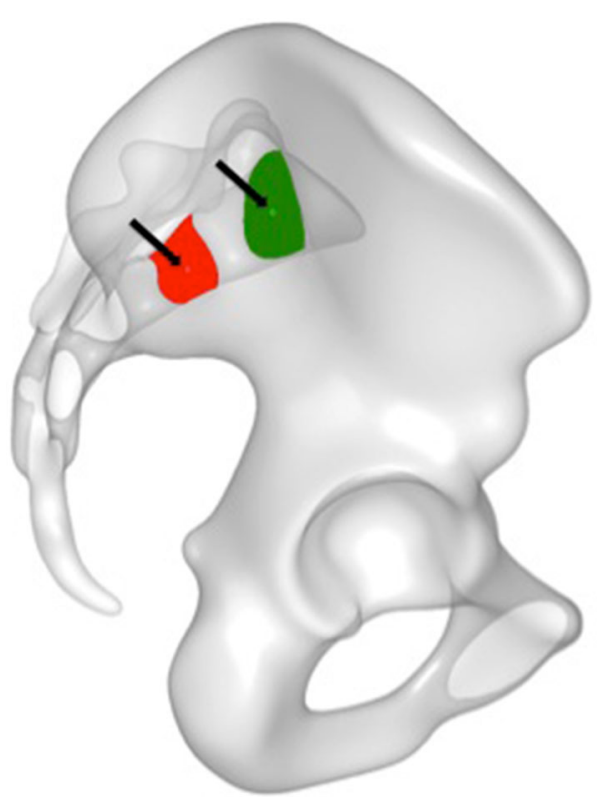

Fig. 2 On a true lateral view from the right side, the green surface area defines the corridor shape through which a transsacral screw can be placed at the level of S1. The red surface area defines the corridor shape through which a transsacral screw can be placed at the level of S2. The small circles (arrows) represent the manually set starting point for the transsacral corridor analysis. In a mapping algorithm, this starting point was transferred automatically from the template pelvis to each pelvis to determine the transsacral corridor axes and diameters of each specific pelvis.

gets hit by the corresponding orthogonal projection ray. The mapped template points are visible as small circles (Fig. 2) located inside the projected regions, representing the available space of the corridors. The cylinder diameter corresponds to the diameter of the largest circle that can be fitted inside each region. Using the two mapped points as 

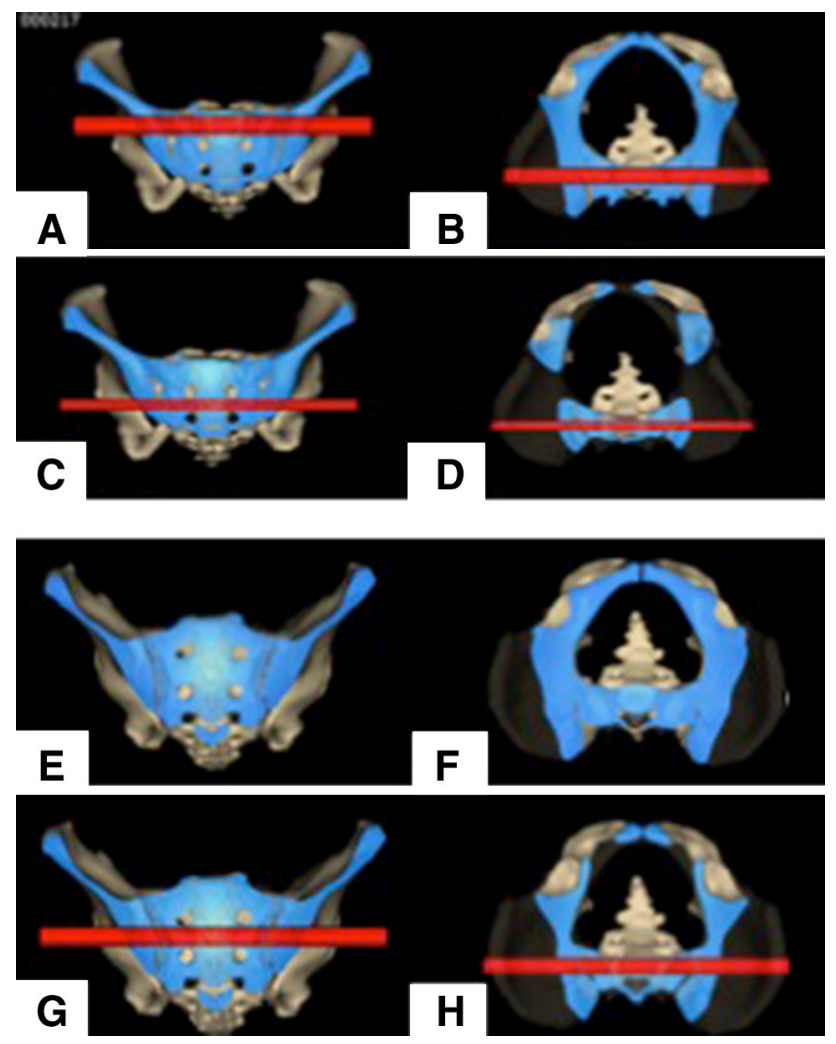

Fig. 3A-H Transsacral corridors (red) at the level of S1 (upper row) and S2 (lower row) are shown for a nondysmorphic-shaped sacrum. Shown are the (A) S1 corridor in coronal and (B) axial slice images, and $(\mathbf{C})$ the S2 corridor in coronal and (D) axial slice images. In a dysmorphic sacrum, no transsacral S1 corridor exists. Shown are the dysmorphic sacrum (E) in the coronal and (F) axial planes. A compensatory larger transsacral S2 corridor exists as shown $(\mathbf{G})$ on coronal and (H) axial slice images.

pivot points, the axes can be tilted for each corridor separately by two angles (alpha, beta) to simulate different viewing directions while generating the orthogonal projections. The two angles are tested iteratively over an angular search range, which is discretized and evaluated for each of these parameter configurations.

This evaluation yields the diameter and the axis of the largest cylinder that fits entirely into the patient-specific corridor. If no space is available, the projection is empty and no cylinder fitting can be performed (Fig. 3).

In our clinical setting, a minimum corridor diameter of at least $9 \mathrm{~mm}$ was defined as a cutoff for placing a $7.3-\mathrm{mm}$ cortical screw to get a tolerance of accuracy of $1 \mathrm{~mm}$ on each side. If no transsacral osseous corridor was prevalent, such pelves were defined as having sacral dysmorphism. The rationale for such CT-based designation of sacral dysmorphism was the continuum of reported radiographicbased criteria for sacral dysmorphism [8].
Statistical Analyses

For statistical analysis, Microsoft ${ }^{\circledR}$ Excel $^{\circledR} 2013$ (Microsoft Inc, Redmond, WA, USA) and the R x64 3.1.2 software program (R Foundation for Statistical Computing, Vienna, Austria) were used. All data are presented as mean and $95 \%$ CI to determine statistical significance. Probability values less than 0.05 were considered significant.

The Ryan procedure with the Welch test (for heterogeneous variances) or the t-test (homogeneous variances) was used for analyses of corridor diameter differences.

The proportions of sacral dysmorphism and corridor sizes $(<9 \mathrm{~mm}$ versus $\geq 9 \mathrm{~mm}$ ) were analyzed with Pearson's chi-square contingence test $(2 \times 2$ or $2 \times 4)$. Linear correlation analyses for S1 and S2 corridor diameters and pairwise testing of corridor diameters with anthropometric data (age, body height, body weight) were performed separately for females and males [15].

\section{Results}

Transsacral Corridor at SI Level and the Proportion of Sacral Dysmorphism

Thirty of $280(11 \%)$ pelves had no transsacral S1 corridor owing to sacral dysmorphism. The maximum cylindrical diameter of the $\mathrm{S} 1$ corridor for the remaining 250 pelves was $12.8 \mathrm{~mm}$ (95\% CI, 12.1-13.5 mm). Setting the diameter threshold at $9 \mathrm{~mm}$ for a secure transsacral $7.3-\mathrm{mm}$ screw placement, theoretically fixation would have been possible in 191 (68\%) of the pelves (Fig. 4).

Transsacral Corridor at S2 Level and Their Dependence on Sacral Dysmorphism

A transverse corridor for S2 was found in 279 of 280 $(99.6 \%)$ pelves. The maximum cylindrical diameter of the $\mathrm{S} 2$ corridor was $11.6 \mathrm{~mm}$ (95\% CI, 11.3-11.9 mm), which was smaller than the $\mathrm{S} 1$ corridor $(\mathrm{p}<0.001)$. Setting the diameter threshold at $9 \mathrm{~mm}$ for a secure transsacral $7.3-\mathrm{mm}$ screw placement, fixation would have been possible in 245 (88\%) of the pelves (Fig. 4).

\section{Correlation of Transsacral Corridor Diameters at S1} and S2 Levels

A decrease in the transsacral S1 corridor diameter was correlated with an increase in the transsacral S2 corridor diameter (males, $-0.311, \mathrm{p}<0.001$ ) (Table 2) (females, 
Fig. 4 A linear distribution for transsacral corridors at the level of S1 (purple line) compared with a sigmoidal distribution at the level of S2 (green line) shows higher variability for osseous corridor shapes on the level of S1.

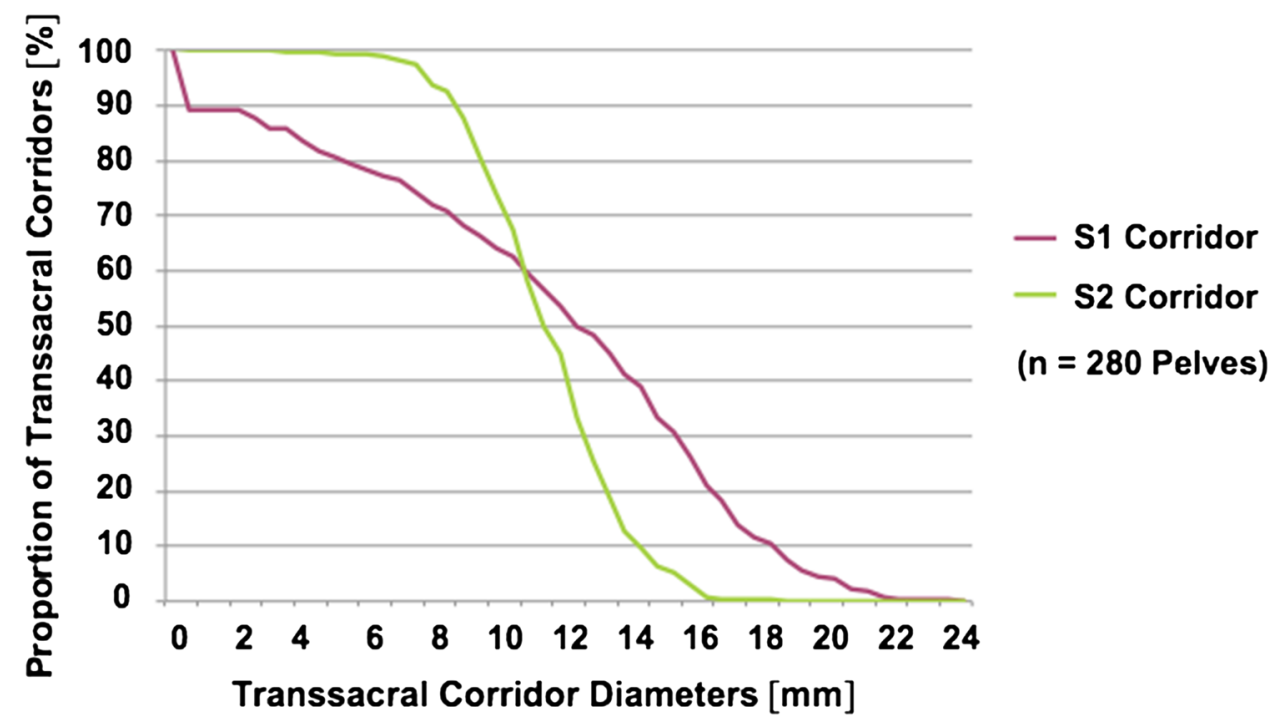

Table 2. Sex-specific correlation analyses for males

\begin{tabular}{|c|c|c|c|c|c|}
\hline Variable & Age & Body height & Body weight & S1 corridor diameter & S2 corridor diameter \\
\hline Age & & $0.987^{*}$ & $-0.232^{\dagger}$ & -0.003 & -0.091 \\
\hline Body height & & & $-0.209^{\dagger}$ & 0.006 & $0.242^{\dagger}$ \\
\hline Body weight & & & & 0.060 & $0.201^{\dagger}$ \\
\hline S1 corridor diameter & & & & & $-0.311^{*}$ \\
\hline S2 corridor diameter & & & & & \\
\hline
\end{tabular}

R values; * $\mathrm{p}<0.05 ;{ }^{\dagger} \mathrm{p}<0.02 ;{ }^{\dagger} \mathrm{p}<0.001$.

Table 3. Sex-specific correlation analyses for females

\begin{tabular}{|c|c|c|c|c|c|}
\hline Variable & Age & Body height & Body weight & S1 corridor diameter & S2 corridor diameter \\
\hline Age & & $-0.257^{\dagger}$ & 0.022 & 0.012 & 0.034 \\
\hline Body height & & & $0.241^{\dagger}$ & $0.218^{*}$ & 0.127 \\
\hline Body weight & & & & 0.041 & 0.043 \\
\hline S1 corridor diameter & & & & & $-0.260^{\dagger}$ \\
\hline
\end{tabular}

R values; * $\mathrm{p}<0.05 ;{ }^{\dagger} \mathrm{p}<0.02$.

$-0.260, \mathrm{p}<0.05$ ) (Table 3), meaning the smaller the S1 corridor diameter the larger S2 corridor diameter.

Sex-specific Differences for the Transsacral Corridors and Correlation With Anthropometric Parameters

The corridor diameters at the S1 and S2 levels were smaller in females than in males (S1: $11.7 \mathrm{~mm}$ [95\% CI, 11.4-12.0 $\mathrm{mm}$ ] versus $13.5 \mathrm{~mm}$ [95\% CI, 12.6-14.4 mm], $\mathrm{p}<0.01$; S2: $10.6 \mathrm{~mm}$ [95\% CI, 10.1-11.1 mm] versus $12.2 \mathrm{~mm}$ [95\% CI, 11.8-12.6 mm], $\mathrm{p}<0.0001)$.
Sacral dysmorphism (no transsacral corridor at the level of S1) was found in 19 of $116(16 \%)$ female pelves and 11 of $164(7 \%)$ male pelves $(\mathrm{p}<0.005)$. Setting the diameter threshold at $9 \mathrm{~mm}$ for a transsacral screw placement, 67 of $116(58 \%)$ female and 126 of $164(77 \%)$ male pelves theoretically would have been placed safely at the S1 level and 97 of $116(84 \%)$ female and 154 of $164(94 \%)$ male pelves would have been placed safely at the S2 level. No transsacral corridor of at least $9 \mathrm{~mm}$ (on level $\mathrm{S} 1$ or level S2) was present in $7 \%$ of males and $1 \%$ of female pelves.

The observed negative correlation of the S1 and S2 corridor diameters was sex-independent (females, -0.260 , 
$\mathrm{p}<0.04$; males $-0.311, \mathrm{p}<0.001)$. Whereas the body height had only a weak correlation with the S1 corridor diameter in females $(0.218 ; \mathrm{p}<0.05)$, a weak correlation of the body height and body weight with the S2 corridor diameter in males $(0.242, \mathrm{p}<0.02 ; 0.201, \mathrm{p}<0.02)$ was observed.

\section{Discussion}

These biomorphometric data support efforts to improve fixation techniques for posterior pelvic ring lesions by using the transsacral S1 osseous corridor for implant placement $[9,11,12,21,26,36]$, primarily described in a case report for a bilateral S1 dislocation [38] and later as a salvage procedure in combination with a posterior tension plate for failed posterior pelvic ring fixations in seven cases [1]. Compared with the oblique sacroiliac screw fixation described by Matta and Saucedo [20], additional fracture pattern like central sacral fractures (Denis Zone III) and bilateral posterior pelvic lesions can be addressed through a unilateral approach, whereas alternative sacroiliac screw fixation from both sides was accompanied with an increased risk of screw misplacement $[9,12]$. Furthermore, in biomechanical studies, increased fixation strength for transsacral screw placement was reported owing to the screw placement in three additional cortices on the contralateral side instead of placing the screw tip in the weaker cancellous bone of the sacral ala and S1 vertebral body $[18,33,39]$. This seems particularly important in the increasing number of insufficiency fractures of the pelvic ring caused by osteoporotic bone quality [14]. Nevertheless, transsacral screw placement is more demanding than iliosacral screw placement [5]. Sex-dependent prevalence of sacral dysmorphism reported in our study (16\% in females and $7 \%$ in males) and too-narrow corridors (depending on the surgeon's diameter-cutoff decision) (Fig. 4) must be excluded to prevent screw misplacements with violation of neurovascular structures [9, 29, 37].

Our study has some limitations. First, CT data sets for different medical indications were segmented, not necessarily representing the cohort group of patients with pelvic ring fractures. Nevertheless, a large number of segmented pelves (280) from patients with a wide age range (19-93 years) were analyzed. Second, only bone surfaces were segmented. This does not facilitate automatic measurement of the inner diameter of the osseous corridors (excluding the cortical thickness). Third, unfractured pelves were investigated, but some degree of persistent fracture malreduction could be present in clinical settings. This must be considered especially for transforaminal (Denis Zone II) fractures, where a 5-mm dislocation results in a $36 \%$ reduction of the osseous S1 corridor at the "waist of the hourglass", when placing an iliosacral screw [28]. The same is true for transsacral screw placement. Using a cylindrical-shaped volume for automatic measurement of the osseous corridor diameters does not respect the ovoidshaped osseous corridor at the level of the S1 vertebra and therefore represents only the maximum osseous corridor height, but not necessarily the larger corridor width $[11,22,39]$, which could facilitate placement of an additional second screw in the same corridor [22].

No transsacral osseous corridor at the level of the S1 vertebra was present in 30 of 280 healthy pelves. With wider use of screw fixations in different positions in the posterior pelvic ring (iliosacral or transsacral), several morphologic variations were described and the terms "dysplastic sacrum" and "sacral dysmorphism" were introduced, however, there is lack of consensus regarding their definitions [2, 4, 7, 22, 29]. Routt et al. [29] described five qualitative radiographic signs for sacral dysplasia based on pelvic-outlet and true lateral views, whereas quantitative parameters were described by others [17, 22]. Kaiser et al. [17] developed a sacral dysmorphic score based on coronal and axial angulation of the upper sacral segment. Mendel et al. [22] reported the lateral sacral triangle configuration in the lateral view. A triangle ratio of 1.5 (calculated by the quotient of the anterior height and width of the first sacral body) represents the boundary ratio for the prevalence of sacral dysmorphism, defined as transsacral corridors with a diameter less than $7.3 \mathrm{~mm}$, unsuitable for screw placement. In contrast to these studies, we defined sacral dysmorphism as the absence of a transsacral corridor at the level of the S1 vertebra, as a high sacral anatomic variability [4] and different corridor diameter cutoffs $(5,9$, or $10 \mathrm{~mm})$ exist for transsacral implant placement based on the implant types used (screws, bars, or nails), implant sizes (5-8 mm diameters), and insertion technique (fluoroscopic-controlled versus computer-guided navigation) [2, 5, 8, 11, 21, 24, 37]. Our study provides additional information regarding transsacral corridor-size distributions and proportions of pelves based on their individually set cutoffs in clinical settings (Fig. 4). Using the largest $10-\mathrm{mm}$ diameter cutoff, as reported by Gardner et al. [8] and Moed and Geer [24], transsacral osseous corridors at the S1 and S2 vertebrae would have been too narrow in $36 \%$ and $26 \%$ of pelves compared with $32 \%$ and $12 \%$ when using the $9-\mathrm{mm}$ cutoff. Measured cylindrical diameters in our study $(\mathrm{S} 1,13 \pm 0.3 \mathrm{~mm}$; S2, $12 \pm 2 \mathrm{~mm}$ ) are similar to those reported by Lee et al. [19] (S1: $14 \pm 4 \mathrm{~mm}$; S2 $11 \pm 3 \mathrm{~mm}$ ) and larger than those reported by Vanderschot et al. [37]. (S1, $8 \pm 0.9 \mathrm{~mm}$; S2, 7 $\pm 3 \mathrm{~mm}$ ). Minor differences in several studies may be attributed to heterogeneity of the groups based on sex or the measurement techniques as discussed in a recent study [11]. 
In cases of sacral dysmorphism or too-narrow transsacral S1 corridors, it may be possible to place only oblique sacroiliac screws, according to Matta and Saucedo [20], but alternative or additional transsacral screw placement at the level of the S2 vertebra may be considered [24, 29]. A compensatory larger transsacral osseous S2 corridor in dysmorphic versus nondysmorphic sacra [7, 8, 11], was confirmed in our study, as shown by a weak negative correlation of the $\mathrm{S} 1$ and $\mathrm{S} 2$ transsacral corridor diameters. Furthermore, the larger range of maximum corridor diameters for S1 compared with the smaller more-sigmoidal distribution for S2 (Fig. 4) shows the greater variability of the $\mathrm{S} 1$ osseous corridor shape and confirms the results of Wagner et al. [39] based on their investigation of 20 healthy pelves.

We observed sacral dysmorphism in more female pelves than in male pelves, however, it was present in pelves of both sexes. Furthermore, corridor diameters were larger in male pelves than in female pelves. This sex-dependency has not been considered routinely in some studies published to date [2, 7, 9, 11, 29]. In contrast, Gardner et al. [8] reported no differences in the proportion of sacral dysmorphism between sexes in their cohort of 50 adult pelves, whereas Hasenboehler et al. [16] found a trend for sexdependent prevalence of sacral dysmorphism $(19 \%$ of female and $12 \%$ of male pelves) in patients with trauma. There is a lack of common definition of sacral dysmorphism and studies are based on different cohort groups (age and sex distribution) [2, 7-9, 11, 16, 22, 24, 29]. Smaller transsacral S1 corridor sizes were observed in females compared with males [23].

We believe that because of the complex and highly individual variance of morphologic features of the sacrum, transsacral implant placement for fixation of posterior pelvic ring lesions remains demanding, and additional research is necessary for precise definition of the terms "sacral dysmorphism" and "dysplastic sacrum". Nevertheless, our findings provide the surgeon with additional information for safe transsacral implant placement. Sacral anatomy and potential transsacral screw corridor diameters are sex-dependent and should be considered in the preoperative CT scan analysis. In contrast to the scientific software program used in our study, three-dimensional volumetric measurement options are not routinely available in clinical software programs and therefore only a twodimensional measurement technique in two-dimensional reformatted images can be used. In axial slice images parallel to the $\mathrm{S} 1$ vertebra endplate the maximum corridor width (anterior border: S1 foramen or iliac wing; posterior border: spinal canal) must be determined, and in an orthogonal slice image reformation in a coronal plane, the corridor height (cranial border: surface of the alar pedicle; caudal border: S1 neuroforamen) must be measured.
Depending on these measurements, the surgeon must decide whether to use transsacral implant fixation or an alternative fixation method (oblique SI screw placement, spinopelvic fixation, anterior iliosacral plating, or posterior ilioiliacal bridging plate fixation).

Acknowledgments We thank Jürgen Schwarz Dr-Ing (Institute of Engineering, Ernst-Abbe Fachhochschule Jena, Germany) for the statistical analysis and G. Kliegis Dr med (Nordcom Medical Systems $\mathrm{GmbH}$, Heikendorf, Germany) for radiologic assistance.

\section{References}

1. Beaule PE, Antoniades J, Matta JM. Trans-sacral fixation for failed posterior fixation of the pelvic ring. Arch Orthop Trauma Surg. 2006;126:49-52.

2. Carlson DA, Scheid DK, Maar DC, Baele JR, Kaehr DM. Safe placement of S1 and S2 iliosacral screws: the "vestibule" concept. J Orthop Trauma. 2000;14:264-269.

3. Collinge C, Coons D, Aschenbrenner J. Risks to the superior gluteal neurovascular bundle during percutaneous iliosacral screw insertion: an anatomical cadaver study. J Orthop Trauma. 2005;19:96-101.

4. Conflitti JM, Graves ML, Chip Routt ML Jr. Radiographic quantification and analysis of dysmorphic upper sacral osseous anatomy and associated iliosacral screw insertions. J Orthop Trauma. 2010;24:630-636.

5. Day CS, Prayson MJ, Shuler TE, Towers J, Gruen GS. Transsacral versus modified pelvic landmarks for percutaneous iliosacral screw placement: a computed tomographic analysis and cadaveric study. Am J Orthop (Belle Mead NJ). 2000;29(9 suppl):16-21.

6. Denis F, Davis S, Comfort T. Sacral fractures: an important problem. Retrospective analysis of 236 cases. Clin Orthop Relat Res. 1988;227:67-81.

7. Farrell ED, Gardner MJ, Krieg JC, Chip Routt ML Jr. The upper sacral nerve root tunnel: an anatomic and clinical study. J Orthop Trauma. 2009;23:333-339.

8. Gardner MJ, Morshed S, Nork SE, Ricci WM, Chip Routt ML Jr. Quantification of the upper and second sacral segment safe zones in normal and dysmorphic sacra. J Orthop Trauma. 2010;24:622-629.

9. Gardner MJ, Routt ML Jr. Transiliac-transsacral screws for posterior pelvic stabilization. J Orthop Trauma. 2011;25:378384.

10. Gras F, Gottschling H, Schroder M, Marintschev I, Reimers N, Burgkart R. Sex-specific differences of the infraacetabular corridor: a biomorphometric CT-based analysis on a database of 523 pelves. Clin Orthop Relat Res. 2015;473:361-369.

11. Gras F, Hillmann S, Rausch S, Klos K, Hofmann GO, Marintschev I. Biomorphometric analysis of ilio-sacro-iliacal corridors for an intra-osseous implant to fix posterior pelvic ring fractures. J Orthop Res. 2015;33:254-260.

12. Gras F, Marintschev I, Wilharm A, Klos K, Muckley T, Hofmann GO. 2D-fluoroscopic navigated percutaneous screw fixation of pelvic ring injuries: a case series. BMC Musculoskelet Disord. 2010;11:153.

13. Grossterlinden L, Rueger J, Catala-Lehnen P, Rupprecht M, Lehmann W, Rucker A, Briem D. Factors influencing the accuracy of iliosacral screw placement in trauma patients. Int Orthop. 2011;35:1391-1396.

14. Guggenbuhl P, Meadeb J, Chales G. Osteoporotic fractures of the proximal humerus, pelvis, and ankle: epidemiology and diagnosis. Joint Bone Spine. 2005;72:372-375. 
15. Hartung J, Elpelt B, Klösener K-H. Statistik, Lehr- und Handbuch der angewandten Statistik. Aufbereitung und Darstellung von Datenmaterial - Deskriptive Statistik. Munich, Germany: Oldenbourg Wissenschaftsverlag; 2005:15-90.

16. Hasenboehler EA, Stahel PF, Williams A, Smith WR, Newman JT, Symonds DL, Morgan SJ. Prevalence of sacral dysmorphia in a prospective trauma population: implications for a "safe" surgical corridor for sacro-iliac screw placement. Patient Saf Surg. 2011;5:8.

17. Kaiser SP, Gardner MJ, Liu J, Routt ML Jr, Morshed S. Anatomic determinants of sacral dysmorphism and implications for safe iliosacral screw placement. J Bone Joint Surg Am. 2014;96:e120.

18. Kraemer W, Hearn T, Tile M, Powell J. The effect of thread length and location on extraction strengths of iliosacral lag screws. Injury. 1994;25:5-9.

19. Lee JJ, Rosenbaum SL, Martusiewicz A, Holcombe SA, Wang SC, Goulet JA. Transsacral screw safe zone size by sacral segmentation variations. J Orthop Res. 2015;33:277-282.

20. Matta JM, Saucedo T. Internal fixation of pelvic ring fractures. Clin Orthop Relat Res. 1989;242:83-97.

21. Mehling I, Hessmann MH, Rommens PM. Stabilization of fatigue fractures of the dorsal pelvis with a trans-sacral bar: operative technique and outcome. Injury. 2012;43:446-451.

22. Mendel T, Noser H, Wohlrab D, Stock K, Radetzki F. The lateral sacral triangle: a decision support for secure transverse sacroiliac screw insertion. Injury. 2011;42:1164-1170.

23. Mendel T, Radetzki F, Wohlrab D, Stock K, Hofmann GO, Noser H. CT-based 3-D visualisation of secure bone corridors and optimal trajectories for sacroiliac screws. Injury. 2013;44:957-963.

24. Moed BR, Geer BL. S2 iliosacral screw fixation for disruptions of the posterior pelvic ring: a report of 49 cases. J Orthop Trauma. 2006;20:378-383.

25. Moed BR, Whiting DR. Locked transsacral screw fixation of bilateral injuries of the posterior pelvic ring: initial clinical series. J Orthop Trauma. 2010;24:616-621.

26. Nork SE, Jones CB, Harding SP, Mirza SK, Routt ML Jr. Percutaneous stabilization of U-shaped sacral fractures using iliosacral screws: technique and early results. J Orthop Trauma. 2001;15:238-246.

27. Osterhoff G, Ossendorf C, Wanner GA, Simmen HP, Werner CM. Percutaneous iliosacral screw fixation in S1 and S2 for posterior pelvic ring injuries: technique and perioperative complications. Arch Orthop Trauma Surg. 2011;131:809-813.

28. Reilly MC, Bono CM, Litkouhi B, Sirkin M, Behrens FF. The effect of sacral fracture malreduction on the safe placement of iliosacral screws. J Orthop Trauma. 2003;17:88-94.
29. Routt ML Jr, Simonian PT, Agnew SG, Mann FA. Radiographic recognition of the sacral alar slope for optimal placement of iliosacral screws: a cadaveric and clinical study. J Orthop Trauma. 1996;10:171-177.

30. Routt ML Jr, Simonian PT, Mills WJ. Iliosacral screw fixation: early complications of the percutaneous technique. J Orthop Trauma. 1997;11:584-589.

31. Sagi HC, Lindvall EM. Inadvertent intraforaminal iliosacral screw placement despite apparent appropriate positioning on intraoperative fluoroscopy. J Orthop Trauma. 2005;19:130133.

32. Surup T, Hänler A, Hohmeier A, Petersik A, von Oldenburg G, Burgkart R. Verfahren zur Referenzmodellerstellung für die Evaluierung CT-basierter Segmentierung des KortikalisSpongiosa-Überganges im Femur. In: Meinzer H-P, Deserno TM, Handels H, Tolxdorff T. eds. Bildverarbeitung für die Medizin 2013. Berlin, Germany: Springer-Verlag; 2013: 259-264.

33. Tabaie SA, Bledsoe JG, Moed BR. Biomechanical comparison of standard iliosacral screw fixation to transsacral locked screw fixation in a type C zone II pelvic fracture model. J Orthop Trauma. 2013;27:521-526.

34. Templeman D, Schmidt A, Freese J, Weisman I. Proximity of iliosacral screws to neurovascular structures after internal fixation. Clin Orthop Relat Res. 1996;329:194-198.

35. Tile M, Helfet DJ, Kellam JF. F Internal Fixation for the Injured Pelvic Ring. Fractures of the Pelvis and Acetabulum. 3rd ed. Philadelphia, PA: Lippincott Williams \& Wilkins; 2003:230-242.

36. Vanderschot P. Treatment options of pelvic and acetabular fractures in patients with osteoporotic bone. Injury. 2007;38:497508.

37. Vanderschot P, Meuleman C, Lefevre A, Broos P. Trans iliacsacral-iliac bar stabilisation to treat bilateral lesions of the sacroiliac joint or sacrum: anatomical considerations and clinical experience. Injury. 2001;32:587-592.

38. Vanderschot PM, Broens PM, Vermeire JI, Broos PL. Trans iliacsacral-iliac bar stabilization to treat bilateral sacro-iliac joint disruptions. Injury. 1999;30:637-640.

39. Wagner D, Kamer L, Rommens PM, Sawaguchi T, Richards RG, Noser H. 3D statistical modeling techniques to investigate the anatomy of the sacrum, its bone mass distribution, and the transsacral corridors. J Orthop Res. 2014;32:1543-1548.

40. Ziran BH, Wasan AD, Marks DM, Olson SA, Chapman MW. Fluoroscopic imaging guides of the posterior pelvis pertaining to iliosacral screw placement. J Trauma. 2007;62:347-356; discussion 356. 